\title{
RESOLUÇÃO DE CONFLITOS E AGRESSIVIDADE: ESCALA SOBRE A PERCEPÇÃO DE EDUCADORES
}

FABRICIO COSTA DE OLIVEIRA

ALESSANDRA DE MORAIS

SEBASTIÃO MARCOS RIBEIRO DE CARVALHO

\section{RESUMO}

Este estudo tem como objetivo estimar as propriedades da Escala de percepção de professores dos comportamentos agressivos de crianças na escola. A pesquisa foi realizada em uma instituição socioeducativa em duas fases. Na primeira, participaram diferentes educadoras que preencheram a escala quanto a cada criança $e$ adolescente que frequentava a instituição ( $N=100)$. Na segunda, as crianças e os adolescentes com as maiores ou as menores pontuações na escala supracitada $(n=60)$ responderam à Children's Action Tendency Scale, que investiga estratégias de resolução de conflitos. Os resultados demonstraram a adequada confiabilidade da escala de percepção. No entanto, indicaram que a avaliação das educadoras não correspondeu à forma como as crianças e adolescentes julgaram os conflitos hipotéticos, uma vez que os meninos foram avaliados como mais agressivos que as meninas na escala de percepção.

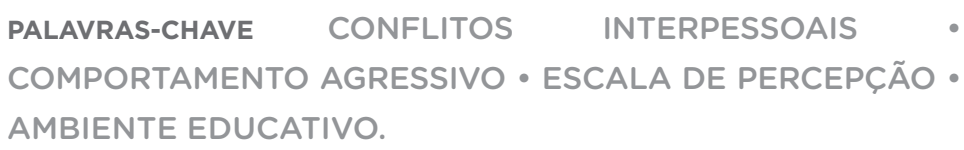




\section{RESUMEN}

Este estudio tiene como objetivo estimar las propiedades de la Escala de percepção de professores dos comportamentos agressivos de crianças na escola. La investigación se realizó en una institución socioeducativa en dos fases. En la primera, participaron diferentes educadores que completaron la escala en lo que se refiere a cada niño y adolescente que concurría a la institución ( $N=100)$. En la segunda, los niños y los adolescentes con las mayores o menores puntuaciones en la escala citada $(n=60)$ respondieron a Children's Action Tendency Scale, que investiga estrategias de resolución de conflicto. Los resultados demostraron la adecuada confiabilidad de la escala de percepción. Sin embargo, señalaron que la evaluación de las educadoras no correspondió a la forma como los niños y adolescentes juzgaron los conflictos hipotéticos, una vez que los niños fueron evaluados como más agresivos que las niñas en la escala de percepción.

PALABRAS CLAVE CONFLICTOS INTERPERSONALES • COMPORTAMIENTO AGRESIVO • ESCALA DE PERCEPCIÓN • AMBIENTE EDUCATIVO.

\section{ABSTRACT}

This study aime to estimate the properties of the Escala de percepção de professores dos comportamentos agressivos de crianças na escola. The research was conducted in a socio-educational institution in two phases. In the first one different educators completed the scale concerning the children and teenagers who attended the institution $(N=100)$. In the second, the children and teenagers with the highest or the lowest scores on the scale above $(n=60)$ responded to the Children's Action Tendency Scale, which investigates strategies of conflict resolution. The results demonstrated adequate reliability of the scale of perception. However, they indicated that the educators' evaluation did not correspond to how children and teenagers judged the hypothetical conflicts since the boys were rated as more aggressive than girls on the perception scale.

KEYWORDS INTERPERSONAL CONFLICT - AGGRESSIVE BEHAVIOR - PERCEPTION SCALE • EDUCATIONAL ENVIRONMENT. 


\section{INTRODUÇÃO}

Os conflitos interpessoais podem ocorrer cotidianamente em diversos ambientes e faixas etárias, sendo possível afirmar que sempre existirão conflitos nas situações de interação social. No entanto, de acordo com Vinha (2003), pode ser um equívoco concebê-los como predominantemente prejudiciais ao desenvolvimento humano ou considerar que devem ser eliminados das relações. Essa visão negativa dos conflitos estaria vinculada às suas consequências ou resultados, que, muitas vezes, podem acarretar problemas como brigas e agressões. Para Leme (2004), tal concepção se baseia no pensamento de que os conflitos estão relacionados apenas ao choque entre indivíduos, como uma condição não bem-vinda.

De acordo com Vicentin (2009), os conflitos têm lugar nas relações entre os indivíduos devido à oposição de ideias, gerando um desequilíbrio tanto interindividual quanto intraindividual, e sua resolução exige um trabalho cognitivo, visto que é preciso que o indivíduo seja capaz de se colocar no lugar do outro e de coordenar as diferentes perspectivas. Conforme Tognetta e Vinha (2011), tais eventos estão presentes 
nas interações e indicam algum tipo de desequilíbrio, sendo passíveis de resoluções pacíficas ou violentas, conforme aspectos cognitivos e afetivos inerentes aos envolvidos. Não obstante, as autoras destacam que os conflitos interpessoais podem ser potencializadores do desenvolvimento humano, dependendo de como são compreendidos e resolvidos.

Leme (2011) explica que o conflito interpessoal pode ser determinado por meio de duas estratégias: o enfrentamento da situação de conflito e a fuga. As situações de enfrentamento podem ser subdivididas em outras duas estratégias: as coercitivas, que utilizam ameaças e força física, e as situações que envolvem o diálogo e as negociações. Nas situações de fuga, a autora destaca que ocorre a interrupção do conflito por falta de oposição.

Os trabalhos de Deluty $(1979,1981,1985)$ apresentam os estilos de resolução de conflitos agressivo, submisso e assertivo. E Vicentin (2009) indica também a existência dos estilos mistos: assertivo-submisso, submisso-agressivo e assertivo-agressivo. Esses estilos são descritos como segue:

- agressivo: há o uso da coerção, violência, desrespeito ao direito, sentimento, ideias e opiniões alheias, expressando ações comportamentais de agressão física e/ou verbal, ameaça, provocação, humilhação, entre outras;

- submisso: leva em consideração as opiniões alheias, deixando de lado suas próprias opiniões; concorda com tudo sem questionar, não enfrentando diretamente a situação conflitante com o outro, usando a fuga ou a esquiva;

- assertivo: há o enfrentamento não violento de resolução de conflito, ou seja, de forma pacífica, sem apelar para ações coercitivas, tendo em vista os direitos, sentimentos, ideias e opiniões dos outros, bem como os próprios, e realizando ações como ouvir, entender, compartilhar, argumentar, compreender, negociar e escolher;

- assertivo-submisso, submisso-agressivo e assertivo-agressivo: consistem em formas de enfrentamento combinadas, uma vez que possuem componentes de mais de uma tendência de resolução de conflitos.

O estilo agressivo de resolução de conflitos pode, segundo Vicentin (2011), acarretar uma série de consequências 
danosas, tanto para o agressor quanto para os outros indivíduos do ambiente. Em relação ao contato com os outros indivíduos do grupo, ocorre o afastamento e, consequentemente, o isolamento da pessoa que expressa tais comportamentos. Além disso, com base em diversos estudos, a autora ressalta que um dos motivos pelos quais se encontra um alto índice de violência na sociedade é a prevalência de maneiras não pacíficas, e, por vezes, violentas, de se resolver as situações de conflito. Para a autora, esse estilo de resolução estaria relacionado, em um primeiro momento, na criança de 7 e 8 anos de idade, com as características do egocentrismo (PIAGET, 1994 [1932]), justificando-se tal comportamento na incapacidade cognitiva de coordenar outras perspectivas com a sua própria, o que a levaria a cometer ações sem as perceber. No adolescente e no adulto, mesmo que tenham essa capacidade de se colocar no lugar do outro, pode haver a dificuldade para empregar tais recursos. Nos indivíduos que não enfrentam as situações de conflitos, o que é uma característica da submissão, as consequências são menos visíveis, porém, bastante danosas. Para Vicentin (2011), as características da submissão como estilo de resolução de conflitos sugerem que o indivíduo ainda é governado pelos outros, não sendo capaz de tomar suas próprias decisões. E, por último, o estilo assertivo, em que o indivíduo leva em consideração as ideias do outro, porém, sem deixar de considerar a sua, estaria, na perspectiva de Vicentin (2011), relacionado à autonomia moral (PIAGET, 1994 [1932]). Essa tendência de resolução de conflito se baseia no diálogo e no respeito mútuo, já que, a fim de que haja uma resolução satisfatória, é preciso descentrar o próprio ponto de vista e, assim, possibilitar a compreensão de que existe o outro na relação, ou seja, pontos de vista diferentes, que às vezes são opostos, sendo necessárias operações de reciprocidade e síntese entre contrários.

Segundo Deluty (1981), as crianças não diferem na capacidade de gerar soluções alternativas na resolução de conflitos interpessoais, mas sim, e de forma significativa, no tipo de alternativas que apresentam. Embora aquelas crianças que apresentam predominantemente respostas submissas ou agressivas também sejam hábeis para gerar alternativas 
assertivas, há um diferença importante no total de respostas em relação àquelas que apresentam mais respostas assertivas. Nessa mesma direção, Vicentin (2009) esclarece que não se devem usar classificações das pessoas, rotulando-as de agressivas, submissas ou assertivas. O que se está em pauta é "qual a forma mais frequente de uma pessoa se comportar em situações de conflito interpessoal” (VICENTIN, 2009, p. 40). Quer dizer, qual o estilo predominantemente utilizado nas diferentes circunstâncias.

Segundo Leme (2004), a agressividade é a tendência de resolução de conflitos interpessoais mais estudada na literatura, provavelmente por implicar maior risco para os envolvidos nos possíveis confrontos. É, ainda, a que apresenta maior dificuldade como objeto de investigação, porque o comportamento dela resultante, a agressão, é uma conduta que, além de episódica, não é facilmente definível; ela assume diferentes formas de manifestação, cuja evolução é diversificada e está sujeita à influência de variáveis tanto biológicas, como psicológicas e sociais. Assim, a agressividade humana, por estar em evidência, passa a ser bastante discutida em diversas áreas do conhecimento humano. A definição do termo varia de acordo com a corrente teórica do pesquisador, o que torna difícil a unanimidade (VINHA, 2000).

Lisboa (2005), apoiada na abordagem ecológica, concebe o comportamento agressivo como um processo proveniente da interação entre a pessoa e seu ambiente físico, social, cultural e histórico. Para a autora, é importante entender a agressividade de acordo com os diferentes contextos nos quais os indivíduos estão inseridos, indicando que, nessa perspectiva, "faz sentido afirmar que uma criança está agressiva e não que é agressiva” (LISBOA, 2005, p. 13).

Lisboa e Koller (2001) descrevem o comportamento agressivo como uma ação que causa e/ou implica danos ou prejuízos a outrem, podendo surgir de duas formas: a confrontativa e a não confrontativa. Nas formas confrontativas ocorrem ações diretas físicas, como chutar, bater, morder, destruir objetos pessoais e de outros, machucar outrem ou a si mesmo, ou verbais, como iniciar discussões, falar palavrões e xingamentos, fazer deboches, ameaças, ridicularizações 
e/ou provocações. Já as formas não confrontativas estão relacionadas a atos hostis indiretos, como atacar a reputação, prejudicar o andamento das atividades, perturbar ambientes e provocar intrigas. A agressividade também pode se modificar quanto à direção e aos objetivos para os quais se destina, diversificando-se conforme os tipos de relações estabelecidos entre o agressor e o alvo da agressão, o que acontece, para as autoras, devido à percepção da autoridade e da posição de hierarquia que o outro ocupa. No caso da agressividade infantil, quando é voltada aos pares - colegas e grupos de iguais - geralmente se expressa em sua forma confrontativa. Quando direcionada aos adultos - pais, familiares e professores - aparece como não confrontativa.

Outro aspecto destacado por Lisboa (2005), atinente à perspectiva ecológica, é que o desenvolvimento humano é visto como um processo contínuo de adaptação entre o indivíduo e o contexto. Dependendo da forma ou função do comportamento agressivo e do contexto no qual se manifesta, ele pode ser considerado adaptativo, não tendo assim como intuito causar danos, mas propiciar a acomodação a um novo meio ou papel social. Esse aspecto tem causado polêmicas e criado dificuldades entre os estudiosos, o que evidencia, para a autora, a necessidade de se desenvolverem técnicas precisas para a identificação dos comportamentos agressivos e o reconhecimento de seus matizes e funções, a fim de se ter uma melhor compreensão desse fenômeno como um processo.

Um ponto comum encontrado nos estudos sobre a agressividade é que, com sua identificação, há maiores possibilidades de se compreender o que, por que e quando acontece, e quais suas consequências. De acordo com Lisboa e Koller (2001), vários métodos têm sido empregados com essa finalidade, como, por exemplo, a observação em ambientes naturais. Esse método tem demonstrado objetividade e confiabilidade, no entanto, demanda muito tempo, além de recursos financeiros e humanos. Por isso, outras estratégias têm sido utilizadas, como a consideração do relato de observadores ligados diretamente ao indivíduo focalizado (professores, colegas e familiares), na medida em que proporcionam informações sobre os comportamentos agressivos de forma mais eficaz e confiável. 
Lisboa e Koller (2001) enfatizam a proficuidade do relato de professores que, segundo elas, podem apresentar aspectos positivos como: objetividade na diferenciação de comportamentos; maior tempo de convivência com as crianças avaliadas, o que possibilita melhor conhecimento de suas características; e habilidade para julgar aspectos qualitativos da interação infantil. Como aspecto negativo, está o fato de que esse tipo de avaliação requisita atenção, disposição e disponibilidade dos professores respondentes, motivo pelo qual têm sido desenvolvidas escalas objetivas, de rápido e fácil preenchimento.

Conforme as autoras, diversos instrumentos que objetivam coletar as informações de professores sobre os comportamentos infantis, como sociabilidade, liderança, atitudes, hiperatividade, dentre outros, podem ser encontrados na literatura internacional, e sobre agressividade, principalmente, em trabalhos norte-americanos. No Brasil, porém, há carência de escalas de avaliação de comportamentos agressivos de crianças (LISBOA; KOLLER, 2001) e não há registros de estudos que diferenciem as formas de classificação, expressão e funções da agressividade, durante os diferentes tempos do ciclo da vida (LISBOA, 2005).

Os estudos de Lisboa $(2001,2005)$ vêm preencher essa lacuna, com a adoção da Escala de percepção de professores dos comportamentos agressivos de crianças na escola (LISBOA; KOLLER, 2001), em que foi possível investigar, no primeiro trabalho, a percepção de comportamentos agressivos em crianças vítimas e não vítimas de violência doméstica, o uso de estratégias de coping - mudanças cognitivas e emocionais, usadas para gerenciar demandas internas e externas, consideradas estressoras - por essas crianças, no ambiente escolar, além dos problemas, relatados por elas, com professores e colegas (LISBOA, 2001); enquanto, no segundo trabalho, as associações entre diferentes processos que ocorrem na esfera interpessoal, como vitimização, amizade e agressividades (LISBOA, 2005).

Este artigo trata do instrumento em pauta, focalizando seus alcances, limites e possíveis contribuições. O objetivo é investigar as avaliações de diferentes educadoras sobre a manifestação de comportamentos agressivos de crianças e adolescentes e relacioná-las com os estilos de resolução de 
conflitos apresentados mediante o julgamento de situações hipotéticas, de forma a estimar as propriedades da Escala de percepção de professores dos comportamentos agressivos de crianças na escola (LISBOA; KOLLER, 2001).

\section{METODOLOGIA}

A pesquisa foi realizada em uma instituição de uma cidade do interior do Estado de São Paulo, que desenvolve, por meio da Secretaria de Assistência Social, um programa destinado ao atendimento de crianças e adolescentes de 7 a 17 anos de ambos os sexos. Além da idade, outros critérios para estar no programa se referem à renda per capita, ao risco social (criminalidade, prostituição, trabalho infantil, violência familiar etc.) e à frequência na educação básica. O programa acontece de segunda a sexta-feira, no período da manhã e da tarde, e o comparecimento das crianças e adolescentes em um dos dois períodos depende do horário em que frequentam a escola. As atividades (refeições, atividades socioeducativas e esportivas) são organizadas durante todo o tempo em que permanecem na instituição.

Cada período tem três turmas: a turma das crianças menores, com idade de 7 a 10 anos; a turma das crianças maiores e/ou pré-adolescentes, com idade de 11 a 12 anos; e a turma dos adolescentes, com idade de 13 a 17 anos. Na época da realização deste estudo, final de 2010 e início de 2011, havia 100 crianças e adolescentes inscritos no programa.

A investigação recebeu parecer favorável do Comitê de Ética em Pesquisa da instituição à qual se vincula (protocolo n. 0555/2010) e foi realizada em duas fases, cujos procedimentos metodológicos relativos a cada uma delas são descritos na sequência.

\section{PRIMEIRA FASE DA PESQUISA \\ PARTICIPANTES}

Nessa etapa, diferentes profissionais preencheram individualmente a Escala de percepção de professores dos comportamentos agressivos de crianças na escola (LISBOA; KOLLER, 2001) referente a cada criança e adolescente que frequentava a instituição 
$(\mathrm{N}=100)$. As profissionais participantes foram: uma coordenadora, de 46 anos de idade, com formação superior em serviço social, há 11 anos no programa, e que exercia funções administrativas, organizacionais, disciplinares, além de auxiliar nos horários das refeições, em eventos e apresentações; três educadoras sociais, todas com formação superior em pedagogia, cada uma sendo responsável por uma turma, em cada período, além de desenvolver atividades culturais, recreativas, de cidadania, entre outras. A educadora da turma 1 (crianças menores) tinha 63 anos e trabalhava há quatro anos no programa; a educadora da turma 2 (crianças maiores e pré-adolescentes), de 47 anos, trabalhava há quatro anos e sete meses no programa; e a educadora da turma 3 (adolescentes) de 34 anos de idade, estava há 11 anos no programa. Completava a equipe uma professora com licenciatura em educação física, de 27 anos de idade, que trabalhava há dois anos no programa, desenvolvendo atividades físicas, de lazer, recreação, competições, festivais, dentre outras. A coordenadora e a educadora física preencheram a escala para cada uma das 100 crianças e adolescentes, uma vez que trabalhavam com todas as turmas. No caso das três educadoras sociais, o preenchimento da escala deu-se apenas para as turmas nas quais atuavam.

Do total de crianças e adolescentes que preencheram a escala de percepção ( $N=100), 56 \%$ frequentavam a instituição onde o estudo foi feito no período da manhã, e $44 \%$ no período da tarde. A maior parte eram meninos (60\%). No que diz respeito à distribuição nas diferentes turmas/idade, 36\% estavam na turma $1,36 \%$, na turma 2 e $28 \%$ na turma 3 . Foi aplicado o teste qui-quadrado a fim de verificar se a distribuição das crianças e adolescentes segundo as turmas/idade e o gênero apresentava diferenças importantes. $\mathrm{O}$ valor encontrado não foi significativo, e com base nisso se considerou a distribuição satisfatória.

\section{INSTRUMENTO}

Utilizou-se, na primeira fase da pesquisa, a Escala de percepção de professores dos comportamentos agressivos de crianças na escola, elaborada por Lisboa e Koller (2001), que passou pelo 
processo de validação de conteúdo por 40 juízes - 20 professores e 20 psicólogos (LISBOA, 2001; LISBOA; KOLLER, 2001). A escala foi construída de modo a permitir aos professores informarem, em cada uma de suas 41 afirmações, a percepção que têm de seus alunos no ambiente escolar. $O$ procedimento de avaliação prevê o cálculo de sete escores, a partir da soma dos pontos marcados pelo professor em cada afirmativa, que variam de 1 (discordo totalmente) a 5 (concordo plenamente) nas seguintes subescalas:

a) escore sobre formas confrontativas de expressão da agressividade percebidas pelo professor, com 20 itens;

b) escore sobre formas não confrontativas, 6 itens;

c) escore sobre a agressão dirigida a professores, com 10 itens;

d) escore sobre a agressão dirigida aos colegas, com 10 itens;

e) escore sobre a agressão dirigida ao âmbito geral, com 6 itens;

f) escore total, o qual será doravante denominado Escala Agressivo Total, abrangendo todos os cinco escores anteriores relacionados à agressividade, com 26 itens;

g) escore dos itens positivos ou pró-sociais, com 15 itens.

Nota-se que a somatória dos itens das subescalas de "a" a "e" é superior a 26 , pelo fato de cada item contemplar, ao mesmo tempo, o tipo de agressividade (confrontativo ou não confrontativo) e o alvo para o qual é dirigida (professores, pares ou indeterminado).

De acordo com as autoras da escala, os itens do tipo pró-social foram inseridos aleatoriamente no instrumento, de maneira a mesclá-los com aqueles que descreviam comportamentos agressivos. Essa estratégia teve dois objetivos: não permitir que o respondente percebesse que o constructo medido pela escala era a agressividade das crianças, evitando-se viés no estudo, e possibilitar um bem-estar aos mesmos, uma vez que os itens sobre agressividade assumem um caráter negativo e podem provocar sentimentos desagradáveis e mal-estar, enquanto os positivos favorecem que os professores indiquem comportamentos mais adaptativos. 
A pontuação da escala de percepção da agressividade vai de 26 (mínima pontuação) a 130 pontos (máxima pontuação). Levando em conta os objetivos deste estudo, serão apresentados somente os dados relativos aos itens de comportamentos agressivos.

\section{SEGUNDA FASE DA PESQUISA \\ PARTICIPANTES}

Com a finalidade de identificar os indivíduos percebidos pelas educadoras como manifestando mais ou menos comportamentos agressivos, foram selecionados aqueles que obtiveram as maiores e as menores pontuações na Escala de Percepção dos Comportamentos Agressivos. Para a composição da amostra dessa etapa da pesquisa, com 60 indivíduos $(\mathrm{n}=60)$, foram levadas em consideração três variáveis: idade (20 indivíduos de cada grupo etário), comportamento agressivo e gênero. Dessa amostra, foram selecionados dez indivíduos com maior pontuação na escala de agressividade e dez com menor pontuação para cada grupo de idade. Quanto à variável gênero, para que a amostra fosse proporcionalmente homogênea em relação à população total $(\mathrm{N}=100)$, uma vez que nesta a quantidade de meninos $(n=60)$ era maior do que a de meninas $(n=40)$, foram considerados seis meninos e quatro meninas para as categorias de maior e menor pontuação na escala de agressividade, somando-se, então, doze meninos e oito meninas em cada uma das faixas etárias. A distribuição da amostra pode ser visualizada no Quadro 1. 
QUADRO 1 - Composição da amostra de crianças e adolescentes participantes da segunda fase da pesquisa

\begin{tabular}{|c|c|c|c|}
\hline $\begin{array}{l}\text { TURMA } \\
\text { (IDADE) }\end{array}$ & $\begin{array}{c}\text { PONTUAÇÃO DE COMPORTAMENTOS } \\
\text { AGRESSIVOS NA ESCALA DE } \\
\text { PERCEPÇÃO }\end{array}$ & GÊNERO & $\begin{array}{c}\text { TOTAL DE } \\
\text { PARTICIPANTES }\end{array}$ \\
\hline \multirow{4}{*}{$\begin{array}{l}\text { TURMA } 1 \\
\text { (07 a } 10 \text { anos) }\end{array}$} & \multirow{2}{*}{10 indivíduos com menor pontuação } & 06 meninos & \multirow{4}{*}{20} \\
\hline & & O4 meninas & \\
\hline & \multirow{2}{*}{10 indivíduos com maior pontuação } & 06 meninos & \\
\hline & & 04 meninas & \\
\hline \multirow{4}{*}{$\begin{array}{l}\text { TURMA } 2 \\
\text { (11 e } 12 \text { anos) }\end{array}$} & \multirow{2}{*}{10 indivíduos com menor pontuação } & 06 meninos & \multirow{4}{*}{20} \\
\hline & & O4 meninas & \\
\hline & \multirow{2}{*}{10 indivíduos com maior pontuação } & 06 meninos & \\
\hline & & 04 meninas & \\
\hline \multirow{4}{*}{$\begin{array}{l}\text { TURMA } 3 \\
\text { (13 a } 17 \text { anos) }\end{array}$} & \multirow{2}{*}{10 indivíduos com menor pontuação } & 06 meninos & \multirow{4}{*}{20} \\
\hline & & O4 meninas & \\
\hline & \multirow{2}{*}{10 indivíduos com maior pontuação } & 06 meninos & \\
\hline & & 04 meninas & \\
\hline \multicolumn{3}{|c|}{ Tamanho da amostra } & 60 \\
\hline
\end{tabular}

Fonte: Dados da pesquisa (elaborado pelos autores, 2013).

\section{INSTRUMENTO}

$\mathrm{O}$ instrumento utilizado na segunda fase da pesquisa foi a Children's Action Tendency Scale - CATS, desenvolvido por Deluty (1979), cuja avaliação se dá mediante a forma como os sujeitos indicam a resolução dos conflitos interpessoais fictícios, com conteúdos de provocações, perdas, frustrações, dentre outros. Na versão original da escala, para cada situação de conflito apresentada seguem-se três alternativas objetivas de respostas (submissa, agressiva e assertiva), dispostas de forma que possam ser comparadas entre si, duas a duas, possibilitando três pares de escolha para cada situação. De acordo com Deluty (1985), a CATS demonstra alta correlação com relatos de pares e professores, e com uma variedade de índices comportamentais, observados em ambientes naturais. Neste estudo, foi empregado o instrumento em sua forma aberta, tal como realizado por Leme (2004) e Vicentin (2009), uma vez que, nesse formato, a interferência nos resultados é menor, já que não limita as respostas a afirmações previamente elaboradas, e permite que o participante expresse com mais liberdade o que faria provavelmente na 
situação apresentada. A versão utilizada foi a apresentada no trabalho de Vicentin (2009). Não obstante foram realizadas adaptações com o propósito de aproximar ao máximo as situações de conflitos que compõem o instrumento da realidade dos participantes.

A CATS foi aplicada individualmente, em forma de entrevista. O procedimento foi filmado e, posteriormente, os dados foram transcritos para a categorização das respostas.

\section{FORMA DE ANÁLISE DOS RESULTADOS}

O programa estatístico usado para a análise dos dados foi o software $\mathrm{IBM}^{\odot}$ SPSS $^{\odot}$ Statistics Version 19,0.

Com o propósito de verificar a fidedignidade da escala de percepção, utilizou-se o coeficiente alfa de Cronbach, que busca averiguar a consistência interna do teste mediante a análise da consistência interna dos itens que o compõem, observando a congruência de cada item do teste com os demais itens do mesmo teste (PASQUALI, 1997). Para se estimar a concordância entre as indicações dos diferentes profissionais participantes no que tange à percepção dos comportamentos agressivos das crianças e dos adolescentes investigados, empregou-se o Coeficiente de Correlação Intraclasses (PESTANA; GAGEIRO, 2005).

Na verificação da normalidade dos dados, observou-se que, para aquelas variáveis em estudo, os resultados no teste de Shapiro-Wilk foram significativos para $\mathrm{p}<0,01$, decidindo-se, assim, pelo emprego dos testes não paramétricos.

Como medida de tendência central dos escores relativos à Escala de Percepção dos Comportamentos Agressivos, no conjunto dos diferentes profissionais, foi calculada a mediana.

Na análise das respostas relativas à CATS (DELUTY, 1979), as categorias foram identificadas com base nas tendências e/ou estilos de resolução de conflitos descritos por Deluty (1979, 1981, 1985), em relação aos estilos puros - agressivo, submisso, assertivo - e Vicentin (2009), no que diz respeito, especialmente, aos estilos mistos - agressivo/submisso, agressivo/assertivo e submisso/assertivo. Além das categorias já apresentadas pelos autores, foi proposta, neste trabalho, 
a categoria agressivo/submisso/assertivo, visto que se pôde observar a presença dos três estilos de resolução interindividual de conflitos em uma única resposta. A verificação da pertinência das categorias foi feita com o auxílio de um juiz com conhecimento na área, sendo então calculado o Índice de Concordância entre o juiz e o pesquisador, que alcançou o valor de $78 \%$, considerado por estar dentro dos critérios para determinar a significância da análise (FAGUNDES, 1999). Em seguida, foram examinadas a frequência e a porcentagem com que os diferentes estilos compareceram e, por esses dados, adotou-se como medida de tendência central a sua mediana.

Para verificar as variações dos dados obtidos nos dois instrumentos empregados, conforme o gênero e a idade, optou-se, respectivamente, pelo emprego dos testes de Mann-Whitney (Prova U) e de Kruskal-Wallis. Para a verificação da significância da diferença entre amostras dependentes foi empregado o Teste de Wilcoxon. O nível de significância $(\alpha)$ considerado foi igual a 0,05 .

\section{RESULTADOS DA PRIMEIRA FASE: A CONFIABILIDADE} DA ESCALA DE PERCEPÇÃO E A CONSISTÊNCIA ENTRE AS AVALIAÇÕES DAS EDUCADORAS

Quanto à fidedignidade da escala de percepção empregada, os coeficientes obtidos se revelaram fortes, no que se relaciona a todas as profissionais respondentes e ao conjunto delas, o que confirma a sua confiabilidade (Tabela 1 ).

TABELA 1 - Coeficientes alfa de Cronbach da Escala Agressivo Total

\begin{tabular}{l|c|c|c|c}
\hline ESCALA & $\begin{array}{c}\text { EDUCADORAS } \\
\text { SOCIAIS }\end{array}$ & $\begin{array}{c}\text { EDUCADORA } \\
\text { FÍSICA }\end{array}$ & COORDENADORA & $\begin{array}{c}\text { CONJUNTO DOS } \\
\text { PROFISSIONAIS }\end{array}$ \\
\hline Agressivo Total & $\alpha=0,908$ & $\alpha=0,898$ & $\alpha=0,963$ & $\alpha=0,941$ \\
\hline
\end{tabular}

Fonte: Dados da pesquisa (elaborada pelos autores, 2013).

Esses dados reiteram aqueles encontrados por Lisboa (2005), em que essa mesma escala foi preenchida por professores para uma amostra de 253 crianças, quando o alfa de Cronbach obtido foi de 0,968 . 
No que concerne à concordância entre as indicações das respondentes, no preenchimento da escala, para a dimensão agressivo total, obteve-se um Coeficiente de Correlação Intraclasses de 0,789, com intervalo de confiança de $95 \%$ entre 0,706 e 0,852 ; com isso, pode-se concluir que existe uma adequada consistência entre as diferentes profissionais respondentes.

Destaca-se a relevância desses resultados, os quais apontam para a coerência das avaliações das diferentes profissionais que preencheram a escala, em relação à percepção que têm dos comportamentos manifestados pelas crianças e adolescentes. Isso evidencia a importância de se levar em conta os relatos dos educadores e, também, as diferentes fontes, na análise de um mesmo fenômeno, assim como a eficácia da escala para tal fim.

RESULTADOS DA SEGUNDA FASE: PERCEPÇÃO DA MANIFESTAÇÃO DA AGRESSIVIDADE E ESTILOS DE RESOLUÇÃO DE CONFLITOS

Em relação às pontuações - em valores medianos - indicadas às crianças e adolescentes pelo conjunto das profissionais, relativas à escala de percepção, observa-se na Tabela 2 que as variações dos valores referentes à percepção da manifestação dos comportamentos agressivos, conforme a idade, não foram significativas, ao se aplicar o Teste de Kruskal-Wallis. 
TABELA 2 - Estatísticas dos dados da aplicação da Escala de Percepção dos Comportamentos Agressivos, segundo a faixa etária

\begin{tabular}{|c|c|c|c|c|c|}
\hline \multirow{2}{*}{ COMPORTAMENTO AGRESSIVO } & \multirow{2}{*}{ IDADE } & \multirow{2}{*}{ MEDIANA } & \multirow{2}{*}{$\left(Q_{1}-Q_{3}\right)^{a}$} & \multirow{2}{*}{$\begin{array}{l}\text { MÉDIA DOS } \\
\text { POSTOS }^{b}\end{array}$} & $x^{2}{ }^{2}{ }^{c}$ \\
\hline & & & & & $P^{d}$ \\
\hline \multirow{3}{*}{ AGRESSIVO TOTAL } & 7 a 10 anos & 45,0 & $(30-56)$ & 30,1 & 0,52 \\
\hline & 11 e 12 anos & 44,0 & $(31-63)$ & 31,2 & 0,974 \\
\hline & 13 a 17 anos & 41,0 & $(33-67)$ & 30,2 & \\
\hline \multirow{3}{*}{ DIRIGIDO À AUTORIDADE } & 7 a 10 anos & 14,0 & $(11-17)$ & 27,5 & 1,14 \\
\hline & 11 e 12 anos & 15,5 & $(12-22)$ & 33,4 & 0,564 \\
\hline & 13 a 17 anos & 14,0 & $(11-26)$ & 30,5 & \\
\hline \multirow{3}{*}{ DIRIGIDO AOS PARES } & 7 a 10 anos & 20,0 & $(13-26)$ & 32,3 & 0,36 \\
\hline & 11 e 12 anos & 18,5 & $(12-28)$ & 30,0 & 0,835 \\
\hline & 13 a 17 anos & 17,0 & $(13-27)$ & 29,1 & \\
\hline \multirow{3}{*}{ DIRIGIDO AO AMBIENTE EM GERAL } & 7 a 10 anos & 12,0 & $(7-15)$ & 29,9 & 0,32 \\
\hline & 11 e 12 anos & 11,5 & $(7-17)$ & 32,2 & 0,849 \\
\hline & 13 a 17 anos & 10,0 & $(8-17)$ & 29,2 & \\
\hline \multirow{3}{*}{ CONFRONTATIVO } & 7 a 10 anos & 34,0 & $(23-42)$ & 29,8 & 0,5 \\
\hline & 11 e 12 anos & 32,0 & $(24-48)$ & 30,9 & 0,975 \\
\hline & 13 a 17 anos & 32,0 & $(25-51)$ & 30,7 & \\
\hline \multirow{3}{*}{ NÃO CONFRONTATIVO } & 7 a 10 anos & 11,5 & $(8-16)$ & 30,4 & 0,22 \\
\hline & 11 e 12 anos & 12,0 & $(7-15)$ & 31,8 & 0,893 \\
\hline & 13 a 17 anos & 11,0 & $(7-16)$ & 29,2 & \\
\hline
\end{tabular}

${ }^{a}(Q 1-Q 3)=$ Intervalo interquartílico.

"Posto = Num conjunto de "n" dados observados, ordena-se em ordem crescente esses dados; em seguida atribui-se um número de ordem a cada dado observado. Denomina-se posto do dado a cada número de ordem atribuído.

${ }^{c} \mathcal{X}_{\mathrm{kW}}=$ valor da estatística de Kruskal-Wallis.

${ }^{d} p=$ probabilidade de se observar um resultado tão ou mais extremo que 0 da amostra, supondo que a hipótese nula seja verdadeira.

Fonte: Dados da pesquisa (elaborada pelos autores, 2013).

Investigou-se ainda se as diferenças entre os escores relacionados com a direção dos comportamentos agressivos eram significativas, uma vez que as medianas apresentadas quando os alvos eram os pares foram superiores às concernentes aos professores. Aos aplicar o Teste de Wilcoxon, dentro de cada grupo de idade, a significância da diferença da direção da agressividade foi confirmada. Contudo, a tendência mais forte foi verificada na turma das crianças de menos idade (turma 1: $\mathrm{z}=3,92 ; \mathrm{p}<0,01$ ), quando realizada a equiparação dos resultados com a turma $2(\mathrm{z}=2,05$; $\mathrm{p}<0,01)$ e a turma $3(\mathrm{z}=2,15 ; \mathrm{p}<0,01)$. 
Os resultados expostos não são suficientes para confirmar o achado na literatura de que as formas de manifestação da agressividade podem se diferenciar pela idade, sendo as agressões do tipo físico mais frequentes em crianças de menor idade e as do tipo verbal ou social em crianças mais velhas (BEE, 2003; BERGER, 2003; SHAFFER, 2005). Além disso, ao se levar em conta que houve uma maior percepção da agressividade dirigida aos pares, em detrimento daquela direcionada aos professores, verifica-se que, quanto menor a idade, maior foi essa diferença, o que indica que, em relação às crianças menores, há mais a agressividade dirigida aos pares do que aos professores.

No que se refere ao gênero, os dados obtidos são apresentados na Tabela 3.

TABELA 3 - Estatísticas dos dados da aplicação da Escala de Percepção dos Comportamentos Agressivos, conforme o gênero

\begin{tabular}{|c|c|c|c|c|c|}
\hline \multirow{2}{*}{ COMPORTAMENTO AGRESSIVO } & \multirow{2}{*}{ GÊNERO } & \multirow{2}{*}{ MEDIANA } & \multirow{2}{*}{$\left(Q_{1}-Q_{3}\right)^{a}$} & \multirow{2}{*}{$\begin{array}{l}\text { MÉDIA DOS } \\
\text { POSTOS }^{\mathrm{b}}\end{array}$} & \multirow{2}{*}{$\frac{M W(U){ }^{c}}{P^{d}}$} \\
\hline & & & & & \\
\hline \multirow{2}{*}{ AGRESSIVO TOTAL } & Meninos & 48,0 & $(38-60)$ & 35,0 & 257 \\
\hline & Meninas & 31,0 & $(27-52)$ & 23,0 & 0,008 \\
\hline \multirow{2}{*}{ DIRIGIDO À AUTORIDADE } & Meninos & 16,0 & $(13-21)$ & 35,0 & 263,5 \\
\hline & Meninas & 11,0 & $(10-16)$ & 23,0 & 0,011 \\
\hline \multirow{2}{*}{ DIRIGIDO AOS PARES } & Meninos & 20,0 & $(10-24)$ & 35,0 & 256,5 \\
\hline & Meninas & 13,0 & $(10-24)$ & 23,0 & 0,008 \\
\hline \multirow{2}{*}{ DIRIGIDO AO AMBIENTE EM GERAL } & Meninos & 13,0 & $(9-16)$ & 35,0 & 271,5 \\
\hline & Meninas & 8,0 & $(6-14)$ & 24,0 & 0,015 \\
\hline \multirow{2}{*}{ CONFRONTATIVO } & Meninos & 36,0 & $(29-46)$ & 36,0 & 245,5 \\
\hline & Meninas & 24,0 & $(21-38)$ & 23,0 & 0,005 \\
\hline \multirow[t]{2}{*}{ NÃO CONFRONTATIVO } & Meninos & 12,0 & $(9-15)$ & 24,0 & 277 \\
\hline & Meninas & 8,0 & $(6-13)$ & 35,0 & 0,02 \\
\hline
\end{tabular}

a $($ Q1-Q3) $=$ Intervalo interquartílico

b Posto = Num conjunto de " $n$ " dados observados, ordena-se em ordem crescente esses dados; em seguida atribui-se um número de ordem a cada dado obsWervado. Denomina-se posto do dado a cada número de ordem atribuído.

${ }^{c}=$ valor da estatística de Mann-Whitney (Prova U)

${ }^{\mathrm{d}} \mathrm{p}=$ probabilidade de se observar um resultado tão ou mais extremo que o da amostra, supondo que a hipótese nula seja verdadeira.

Fonte: Dados da pesquisa (elaborada pelos autores, 2013)

Observa-se que os meninos obtiveram maiores pontuações, em comparação àquelas alcançadas pelas meninas. Ressalte-se que, no emprego do Teste de Mann-Whitney, essas diferenças foram tidas como estatisticamente significativas. 
Pode-se afirmar, com base nesses resultados, que as educadoras participantes consideraram que os meninos manifestam mais comportamentos agressivos que as meninas. Esses resultados confirmam aqueles encontrados por Lisboa (2001, 2005), em que as meninas são percebidas pelos professores (LISBOA, 2001) e pelos professores e colegas (LISBOA, 2005) como menos agressivas que os meninos.

Em relação aos resultados dos estilos de resolução de conflitos, verificou-se que o estilo que apresentou a maior pontuação foi o agressivo (mediana $=25,00$ ) e, em seguida, o estilo submisso (mediana=22,22). Em terceira posição, apareceram os estilos mistos agressivo/submisso (mediana=11,11) e submisso/assertivo (mediana=11,11). Pelo fato de as medianas dos estilos agressivo e submisso estarem próximas, pode-se afirmar que houve uma predominância dessas duas tendências nas respostas dos participantes. Além disso, essa marca dos estilos agressivo e submisso também se fez presente por meio do estilo misto agressivo/submisso, o qual apareceu com a terceira pontuação nas medianas, ao lado do submisso/assertivo. Os valores obtidos nas respostas do tipo assertivo e do tipo misto agressivo/submisso/assertivo com medianas zero expressam que pelo menos $50 \%$ dos participantes não demonstraram essas tendências na forma como resolveram os conflitos apresentados. Com base nesses casos, conclui-se que, em quase todos os estilos em que a assertividade esteve presente, a quantidade de respostas foi muito baixa.

No que diz respeito à variação dos valores obtidos nos diferentes estilos conforme a idade, as medianas com maior variação foram aquelas relativas ao estilo submisso/assertivo, em que os valores diminuíram à medida que as idades aumentaram. Essas variações foram significativas no Teste de Kruskal-Wallis (Tabela 4), diferentemente dos demais estilos, em que as diferenças não foram significativas. 
TABELA 4 - Estatísticas dos dados da segunda fase da pesquisa, referentes aos estilos de resolução de conflitos, segundo a faixa etária

\begin{tabular}{|c|c|c|c|c|c|}
\hline \multirow{2}{*}{$\begin{array}{l}\text { ESTILO DE RESOLUÇÃO } \\
\text { DE CONFLITOS }\end{array}$} & \multirow{2}{*}{ IDADE } & \multirow{2}{*}{ MEDIANA } & \multirow{2}{*}{$Q_{1}-Q_{3}^{a}$} & \multirow{2}{*}{$\begin{array}{l}\text { MÉDIA DOS } \\
\text { POSTOS }^{\mathrm{b}}\end{array}$} & \multirow{2}{*}{$\frac{x_{\mathrm{kW}}{ }^{\mathrm{c}}}{\mathrm{P}^{\mathrm{d}}}$} \\
\hline & & & & & \\
\hline \multirow{3}{*}{ AGRESSIVO } & 7 a 10 anos & 12,0 & $(0-42)$ & 24,3 & 3,84 \\
\hline & 11 e 12 anos & 29,0 & $(11-53)$ & 33,1 & 0,147 \\
\hline & 13 a 17 anos & 33,0 & $(22-44)$ & 34,1 & \\
\hline \multirow{3}{*}{ SUBMISSO } & 7 a 10 anos & 22,0 & $(11-33)$ & 31,3 & 2,88 \\
\hline & 11 e 12 anos & 12,0 & $(3-24)$ & 25,6 & 0,237 \\
\hline & 13 a 17 anos & 24,0 & $(11-42)$ & 34,7 & \\
\hline \multirow{3}{*}{ ASSERTIVO } & 7 a 10 anos & 0,0 & $(0-11)$ & 28,9 & 0,56 \\
\hline & 11 e 12 anos & 0,0 & $(0-13)$ & 32,5 & 0,757 \\
\hline & 13 a 17 anos & 0,0 & $(0-11)$ & 30,2 & \\
\hline \multirow{3}{*}{ AGRESSIVO/SUBMISSO } & 7 a 10 anos & 11,0 & $(3-22)$ & 26,6 & 2,74 \\
\hline & 11 e 12 anos & 24,0 & $(0-33)$ & 35,3 & 0,255 \\
\hline & 13 a 17 anos & 11,0 & $(0-31)$ & 29,6 & \\
\hline \multirow{3}{*}{ AGRESSIVO/ASSERTIVO } & 7 a 10 anos & 0,0 & $(0-11)$ & 26,9 & 1,76 \\
\hline & 11 e 12 anos & 11,0 & $(0-11)$ & 33,5 & 0,415 \\
\hline & 13 a 17 anos & 5,5 & $(0-11)$ & 31,1 & \\
\hline \multirow{3}{*}{ SUBMISSO/ASSERTIVO } & 7 a 10 anos & 28,0 & $(11-38)$ & 41,4 & 13,59 \\
\hline & 11 e 12 anos & 11,0 & $(0-20)$ & 28,0 & 0,001 \\
\hline & 13 a 17 anos & 5,5 & $(0-11)$ & 22,1 & \\
\hline \multirow{3}{*}{$\begin{array}{l}\text { AGRESSIVO/SUBMISSO/ } \\
\text { ASSERTIVO }\end{array}$} & 7 a 10 anos & 0,0 & $(0-11)$ & 35,0 & 5,2 \\
\hline & 11 e 12 anos & 0,0 & $(0-0)$ & 27,7 & 0,074 \\
\hline & 13 a 17 anos & 0,0 & $(0-0)$ & 28,9 & \\
\hline
\end{tabular}

a $(Q 1-Q 3)=$ Intervalo interquartílico

'Posto = Num conjunto de "n" dados observados, ordena-se em ordem crescente esses dados; em seguida atribui-se um número de ordem a cada dado observado. Denomina-se posto do dado a cada número de ordem atribuído.

${ }^{\mathrm{c}} \boldsymbol{x}^{2}{ }_{\mathrm{kW}}=$ valor da estatística de Kruskal-Wallis

${ }^{\mathrm{d}} \mathrm{p}=$ probabilidade de se observar um resultado tão ou mais extremo que o da amostra, supondo que a hipótese nula seja verdadeira.

Fonte: Dados da pesquisa (elaborada pelos autores, 2013).

Neste estudo não foram encontradas, assim como em Leme (2004) e Vicentin (2009), diferenças marcantes relativas à idade das crianças e adolescentes participantes, com exceção de um dos estilos, no caso o estilo misto submisso/assertivo, cuja diminuição também pôde ser identificada nesta pesquisa, conforme o aumento da faixa etária. Na categorização dos dados, foi possível reconhecer que a resposta 
majoritária desse estilo nas crianças de menor faixa etária foi aquela em que as mesmas, para resolverem o conflito proposto, recorriam à ajuda de um adulto. Essa estratégia foi considerada como mista assertiva/submissa por se tratar de indivíduos com repertório reduzido de estratégias de resolução de conflitos e menor capacidade cognitiva. Entende-se como assertivo solicitar ajuda ao adulto, porém, a estratégia não deixa de ser também submissa, já que busca a ação da autoridade. Quando a autoridade era requisitada com o intuito de aplicar algum tipo de sanção a outrem, no sentido de vingança, a tendência de resolução foi igualmente considerada agressiva. Sobretudo nessas situações foi possível encontrar o novo estilo misto: submisso/agressivo/assertivo.

Ao assinalar os constantes conflitos com que a criança se depara ao longo da vida, Menin (1996) ressalta que nem sempre as ações da autoridade para lidar com eles partem na direção da construção da autonomia e, contrariamente, fortalecem situações de submissão e coação, intensificando eventos de agressividade na criança e entre as crianças, causando danos a ela e ao grupo ao qual pertence. Vicentin (2011) enfatiza que a criança só conseguirá resolver seus conflitos de forma satisfatória quando ocorrer a diminuição das características da tendência egocêntrica, ou seja, quando a criança passar a apresentar relações de reciprocidade com o outro. Sobre as necessidades cognitivas e afetivas para resoluções de conflitos interindividuais satisfatórias, Vicentin (2011) alude à necessidade da intervenção do adulto com as crianças com menos de dez anos de idade, justamente por disporem de menos recursos cognitivos e afetivos. Contudo, todas as ações devem estar embasadas em formas construtivas de resolver os conflitos, buscando com isso a autonomia da criança (VINHA, 2000).

Em relação ao gênero, não foram verificadas variações significativas entre os valores dos diferentes estilos investigados, tal se observa na Tabela 5 . 
TABELA 5 - Estatísticas dos dados da segunda fase da pesquisa, referentes aos estilos de resolução de conflitos, segundo o gênero

\begin{tabular}{|c|c|c|c|c|c|}
\hline \multirow{2}{*}{$\begin{array}{l}\text { ESTILO DE RESOLUÇÃO } \\
\text { DE CONFLITO }\end{array}$} & \multirow{2}{*}{ GÊNERO } & \multirow{2}{*}{ MEDIANA } & \multirow{2}{*}{$\left(Q_{1}-Q_{3}\right)^{a}$} & \multirow{2}{*}{$\begin{array}{l}\text { MÉDIA DOS } \\
\text { POSTOS }^{b}\end{array}$} & \multirow{2}{*}{$\frac{M W(U)^{c}}{P^{d}}$} \\
\hline & & & & & \\
\hline \multirow{2}{*}{ AGRESSIVO } & Menino & 22,0 & $(11-44)$ & 29,0 & 386 \\
\hline & Menina & 29,0 & $(11-44)$ & 32,0 & 0,484 \\
\hline \multirow{2}{*}{ SUBMISSO } & Menino & 22,0 & $(11-33)$ & 30,0 & 416 \\
\hline & Menina & 22,0 & $(0-33)$ & 31,0 & 0,081 \\
\hline \multirow{2}{*}{ ASSERTIVO } & Menino & 0,0 & $(0-11)$ & 32,0 & 384 \\
\hline & Menina & 0,0 & $(0-11)$ & 28,5 & 0,411 \\
\hline \multirow{2}{*}{ AGRESSIVO/SUBMISSO } & Menino & 11,0 & $(0-31)$ & 30,0 & 408 \\
\hline & Menina & 12,0 & $(3-24)$ & 31,5 & 0,71 \\
\hline \multirow{2}{*}{ AGRESSIVO/ASSERTIVO } & Menino & 0,0 & $(0-11)$ & 29,0 & 380 \\
\hline & Menina & 5,5 & $(0-12)$ & 33,0 & 0,393 \\
\hline \multirow{2}{*}{ SUBMISSO/ASSERTIVO } & Menino & 11,0 & $(0-31)$ & 32,0 & 388 \\
\hline & Menina & 11,0 & $(0-12)$ & 29,0 & 0,494 \\
\hline \multirow{2}{*}{$\begin{array}{l}\text { AGRESSIVO/SUBMISSO/ } \\
\text { ASSERTIVO }\end{array}$} & Menino & 0,0 & $(0-0)$ & 28,0 & 357 \\
\hline & Menina & 0,0 & $(0-8)$ & 34,0 & 0,068 \\
\hline
\end{tabular}

a $($ Q1-Q3) $=$ Intervalo interquartílico.

b Posto = Num conjunto de " $n$ " dados observados, ordena-se em ordem crescente esses dados; em seguida atribui-se um número de ordem a cada dado observado. Denomina-se posto do dado a cada número de ordem atribuido.

${ }^{c}=$ valor da estatística de Mann-Whitney (Prova $\left.U\right)$

${ }^{\mathrm{a}} \mathrm{p}=$ probabilidade de se observar um resultado tão ou mais extremo que o da amostra, supondo que a hipótese nula seja verdadeira.

Fonte: Dados da pesquisa (elaborada pelos autores, 2013).

Novamente, é possível comparar os resultados sobre os estilos de resolução de conflitos com aqueles salientados nas pesquisas de Leme e Vicentin. Leme (2004) realizou dois estudos em que investigou os estilos de resolução de conflitos de alunos de escolas públicas e privadas. No primeiro, aplicou a CATS em sua forma objetiva, com situações de conflitos e alternativas de estratégias de resolução. No segundo, a CATS foi utilizada na versão aberta, em que o próprio indivíduo deveria propor formas de resolução às situações apresentadas, assim como a presente investigação. O primeiro estudo mostrou que os meninos revelaram uma maior tendência ao estilo agressivo, e as meninas, ao assertivo. No segundo 
estudo, tanto os meninos como as meninas apresentaram a submissão e a agressividade como as duas tendências dominantes, sendo que, entre ambas as tendências, os meninos apresentaram escores médios superiores na agressividade e as meninas na submissão. Quanto às demais tendências, as meninas apontaram mais as assertivas e os meninos, as submisso-agressivas. Vicentin (2009), por sua vez, pesquisou se sujeitos com histórico de dependência química na família resolveriam os conflitos de forma diferente dos indivíduos sem esse histórico familiar. A investigação foi realizada com adolescentes que tinham problemas de alcoolismo na família e adolescentes que não tinham. Os resultados indicaram que a predominância de estratégias submissas nesses adolescentes, seguidas das agressivas. Em uma análise mais apurada, não foram encontradas diferenças significativas entre faixa etária, gênero e filhos de pais com e sem problemas de alcoolismo. Embora o resultado referente ao gênero não tenha sido significativo, ele mostrou que os sujeitos do sexo masculino tendiam a utilizar estratégias agressivas, os do sexo feminino, as estratégias submissas.

Os resultados da presente pesquisa se aproximam daqueles dos estudos de mencionados de Leme e Vicentin, nos quais os estilos com maior predominância foram os agressivos e submissos. Contudo, em relação às variações de acordo com o gênero, não se confirmou o verificado por Leme, já que não foram encontradas diferenças significativas, na amostra investigada, entre os meninos e as meninas no modo de resolução de conflitos.

Não obstante, é intrigante notar que, diferentemente dos resultados referentes à resolução de conflitos, na escala de percepção houve diferença significativa na percepção das profissionais quanto à manifestação da agressividade, na qual os meninos foram avaliados como apresentando mais comportamentos agressivos que as meninas. Essa propensão foi confirmada por Lisboa $(2001,2005)$.

Valendo-se das diferenças entre os dados coletados pelos dois instrumentos, nesta pesquisa, podem ser formuladas duas suposições, não necessariamente excludentes entre si. A primeira seria a de que a percepção das educadoras em 
relação à manifestação da agressividade, de acordo com o gênero, não correspondeu à forma como as meninas e os meninos julgaram os conflitos hipotéticos, pelo fato de haver uma predisposição por parte das educadoras a considerar, ou a esperar, que os meninos apresentem mais comportamentos agressivos que as meninas. A segunda conjetura seria a de que, no ambiente estudado, os meninos manifestam mais comportamentos agressivos que as meninas, mas, na forma de julgarem situações de conflitos, tais inclinações não aparecem. Em relação a ambas as formulações, é possível, por conseguinte, apontar para as influências das expectativas sociais e culturais sobre a percepção e manifestação do comportamento agressivo no contexto educativo.

De acordo com Vicentin (2009), as diferenças dessa natureza podem estar relacionadas a aspectos culturais, sendo até mesmo adotadas sanções diferentes para cada um dos gêneros. Leme (2004), ao destacar o papel dos pais, professores e da cultura na aprendizagem de modelos, frisa que os meninos gozam de maior liberdade para expressar agressividade, enquanto as meninas costumam sofrer a retirada de aprovação quando agem de modo não submisso. Segundo Lisboa (2005), a literatura, de forma geral, indica que culturalmente se tem a expectativa de que as meninas sejam mais dóceis, tolerantes e atenciosas. Além disso, para a autora, os meninos têm sido reconhecidos nas pesquisas como mais agressivos que as meninas, em tipos de agressividade externalizada, definida como todo comportamento físico e/ou verbal que tem a intenção de causar dano a outrem. Já as meninas mostram mais a agressividade relacional, tida como uma forma indireta e intencional de agressividade voltada para a exclusão social e o prejuízo das relações de amizade. No estudo de Lisboa (2005), tal como relatado anteriormente, os meninos foram percebidos pelos professores como mais agressivos que as meninas, assim como por seus colegas. Entretanto, quando aplicada uma escala de autopercepção, os meninos não foram considerados mais agressivos que as meninas. Diante desses resultados, a autora apresenta duas possibilidades: a de que os meninos realmente apresentam mais formas externalizadas de agressividade, visivelmente 
identificadas pelos professores e colegas, ou de que pode haver estereótipos culturais de que os meninos são mais agressivos, que influenciariam a visão dos professores e colegas.

Esses levantamentos demonstram como a dimensão do gênero deve ser avaliada com cautela, tal como advertem Koller e Bernardes (1997) ao discorrer sobre as inconsistências nos achados a esse respeito. Essa é uma preocupação da psicologia do desenvolvimento e indica a necessidade de mais estudos sobre a questão, que levem em conta avaliações aguçadas e contextuais.

\section{CONSIDERAÇÕES FINAIS}

Esta investigação permitiu verificar a confiabilidade da escala de percepção no que diz respeito à sua consistência interna, assim como a adequada concordância entre as diferentes educadoras respondentes a propósito dos mesmos comportamentos. Apontou-se para a relevância de levar em consideração a perspectiva de diferentes profissionais que trabalham diretamente com as crianças e adolescentes pesquisados quanto à percepção de eventos de condutas agressivas e, dessa maneira, reconhecer a concordância nas indicações, mesmo em se tratando de atuações distintas.

Os resultados confirmaram ainda aqueles encontrados em outros trabalhos, mostrando que o emprego da escala de percepção pode conduzir ou confirmar formulações que reiteram a existência de uma diferença importante entre o gênero na percepção da manifestação da agressividade. Esse aspecto é igualmente corroborado na literatura mediante explicações, principalmente, sociais e culturais, o que representa mais um indicativo da eficácia do instrumento. Não obstante, devem ser consideradas as advertências sobre as inconsistências nos achados a respeito das diferenças de gêneros, que preocupam os pesquisadores e indicam a necessidade de mais estudos a respeito. Essas inconsistências foram reveladas mediante o emprego da escala de resolução de conflitos, visto que houve diferenças entre os resultados desta investigação e os de outros estudos. Além disso, evidenciou-se a discrepância entre a percepção das educadoras e as 
formas de resolução de conflitos apresentadas pelas crianças e adolescentes participantes.

Quanto aos estilos de resolução de conflitos, corroboraram-se os resultados de pesquisas atuais brasileiras ao se demonstrar que as principais estratégias utilizadas pelas crianças e adolescentes na resolução de conflitos fictícios, independentemente da idade e do gênero, são as agressivas e as submissas. No que concerne ao estilo assertivo, este aparece de forma quase irrisória dentre as demais tendências, o que também vai ao encontro de pesquisas citadas neste estudo. Questiona-se a baixa incidência de respostas nesse estilo, já que a assertividade estaria relacionada ao respeito mútuo, às ações de falar e ouvir, às estratégias de negociação, à generosidade e à solidariedade, que são de suma importância para a convivência nos diferentes contextos.

Por fim, é possível afirmar que a utilização da escala de percepção denota importantes implicações educacionais, ao possibilitar a investigação da manifestação da agressividade em ambientes educativos, podendo fundamentar e instrumentalizar o planejamento de programas preventivos e de intervenções, voltados para a construção de ambientes favoráveis ao desenvolvimento integral do ser humano. Apesar dos alcances e contribuições desse instrumento, faz-se necessário advertir que as proposições éticas concernentes ao seu uso devem ser levadas em conta, já que estão diretamente relacionadas com o reconhecimento de seus limites. No que se refere aos fins que devem motivar seu emprego, estes devem ser, prioritariamente, voltados para o desenvolvimento de pesquisas e para a fundamentação de estratégias educativas, evitando-se rotulações, discriminações ou o emprego de medidas coercitivas e punitivas. Questões de validação também devem ser averiguadas e pontuadas. Reitera-se, ainda, que o uso exclusivo de um único instrumento dessa natureza pode incorrer em riscos e julgamentos apressados, além de instaurar limitações importantes, sendo recomendável sua combinação com outros recursos ou instrumentos, dentro de uma constante postura crítica. 


\section{REFERÊNCIAS}

BEE, H. A criança em desenvolvimento. Porto Alegre: Artes Médicas, 2003.

BERGER, K.S. O Desenvolvimento da Pessoa: da infância à adolescência. Rio de Janeiro: LTC, 2003.

DELUTY, R. H. Children's Action Tendency Scale: a self-report measure of aggressiveness, assertiveness, and submissiveness in children. Journal of Consulting and Clinical Psychology, v. 47, n. 6, p. 1061-1071, 1979.

Alternative-thinking ability of aggressive, assertive, and submissive children. Cognitive Therapy and Research, v. 5, n. 3, p. 309-312, 1981.

Cognitive mediation of aggressive, assertive and submissive behavior in children. International Journal of Behavior Development, v. 8, p. 355-369, 1985.

FAGUNDES, A. J. F. M. Descrição, definição e registro de comportamento. São Paulo: Edicon, 1999.

IBM $^{\odot}$ SPSS $^{\odot}$ Statistics, Version 19,0. An IBM Company, 2010. 1 Cd-Rom.

KOLLER, S. H.; BERNARDES, N. M. G. Desenvolvimento moral pró-social: semelhanças e diferenças entre os modelos teóricos de Eisenberg e Kohlberg. Estudos de Psicologia, Natal, v. 2, n. 2, p. 223-262, dez. 1997.

LEME, M. I. S. Resolução de conflitos interpessoais: interações entre cognição e afetividade na cultura. Psicologia: Reflexão e Crítica, Porto Alegre, v. 17, n. 3, p. 367-380, 2004.

O diretor escolar e a gestão de conflitos na escola. In: TOGNETTA, L. R. P.; VINHA, T. P. (Org.). Conflitos na instituição educativa: perigo ou oportunidade? Contribuição da Psicologia. Campinas: Mercado de Letras, 2011. p.161-190.

LISBOA, C. S. M. Estratégias de coping e agressividade: um estudo comparativo entre crianças vítimas e não vítimas de violência doméstica. 2001. Dissertação (Mestrado em Psicologia) - Curso de Pós-Graduação de Psicologia do Desenvolvimento, Universidade Federal do Rio Grande do Sul, Porto Alegre, 2001.

Comportamento agressivo, vitimização, e relações de amizade de crianças em idade escolar: fatores de risco e proteção. 2005. Tese (Doutorado em Psicologia) - Curso de Pós-Graduação de Psicologia do Desenvolvimento, Universidade Federal do Rio Grande do Sul, Porto Alegre, 2005.

LISBOA, C. S. M.; KOLLER, S. H. Construção e validação de conteúdo de uma escala de percepção, por professores, dos comportamentos agressivos de crianças na escola. Psicologia em Estudo, v. 6, n. 1, p. 59-69, 2001.

MENIN, M. S. S. Desenvolvimento moral: refletindo com pais e educadores. In: MACEDO, L. (Org.). Cinco estudos de educação moral. São Paulo: Casa do Psicólogo, 1996. p. 37-104.

PASQUALI, L. Psicometria: teoria e aplicações. Brasília: Ed. Universidade de Brasília, 1997. 
PESTANA, M. H.; GAGEIRO, J. N. Análise de dados para as Ciências Sociais: a complementaridade do SPSS. 4. ed. Lisboa: Sílabo, 2005.

PIAGET, J. 0 juízo moral na criança. São Paulo: Summus, 1994. (Original publicado em 1932).

SHAFFER, D. R. Psicologia do desenvolvimento: infância e adolescência. São Paulo: Pioneira Thomson Learning, 2005.

TOGNETTA, L. R. P.; VINHA, T. P. Apresentação. In: TOGNETTA, L. R. P.; VINHA, T. P. (Org.). Conflitos na instituição educativa: perigo ou oportunidade? Contribuição da Psicologia. Campinas: Mercado de Letras, 2011. p. 11-19.

VICENTIN, V. F. Condições de vida e estilos de resolução de conflito entre adolescentes. 2009. Tese (Doutorado em Psicologia) - Instituto de Psicologia, Universidade de São Paulo, São Paulo, 2009.

Estilos de resolução de conflitos interpessoais: o que a escola pode fazer? In: TOGNETTA, L. R. P.; VINHA, T. P. (Org.). Conflitos na instituição educativa: perigo ou oportunidade? Contribuição da Psicologia. Campinas: Mercado de Letras, 2011. p. 229-264.

VINHA, T. P. O educador e a moralidade infantil: uma visão construtivista. Campinas: Mercado de Letras; São Paulo: FAPESP, 2000.

Os conflitos interpessoais na relação educativa. 2003. Tese (Doutorado em Educação) - Faculdade de Educação, Unicamp. Campinas, 2003.

\section{FABRICIO COSTA DE OLIVEIRA}

Educador físico, mestre em Educação pelo Programa de Pós-Graduação da Faculdade de Filosofia e Ciências da Universidade Estadual Paulista "Júlio de Mesquita Filho" (Unesp), Marília, SP. Professor técnico de Esporte e Lazer do Serviço Social da Indústria (Sesi). Professor mestre do Curso de Educação Física da Universidade de Marília (Unimar) professor_fabricioco@yahoo.com.br

\section{ALESSANDRA DE MORAIS}

Psicóloga, mestre e doutora em Educação pela Universidade Estadual Paulista "Júlio de Mesquita Filho" (Unesp). Professora doutora assistente do Departamento de Psicologia da Educação e do Programa de Pós-Graduação em Educação da Faculdade de Filosofia e Ciências da Unesp, Marília, SP alemorais.shimizu@gmail.com 


\section{SEBASTIÃO MARCOS RIBEIRO DE CARVALHO}

Matemático e pedagogo. Professor doutor assistente do Departamento de Psicologia da Educação da Faculdade de Filosofia e Ciências da Universidade Estadual Paulista

“Júlio de Mesquita Filho" (Unesp), Marília, SP

smrc60@gmail.com 